\title{
High-energy Flux Density Extracorporeal Shock-wave Therapy Versus Therapeutic Steroid Injection in Costochondritis: A Single-Blind, Randomised Controlled Study
}

\section{Extrakorporale Stoßwellentherapie mit hoher Energieflussdichte im Vergleich zur therapeutischen Steroidinjektion bei Costochondritis: Eine einfach blinde, randomisierte, kontrollierte Studie}

Authors

Halil Çiftçii ${ }^{10}$, Ömer Gezginaslan²

Affiliations

1 Thoracic Surgery, University of Health Sciences, Umraniye Training and Research Hospital, Istanbul, Turkey

2 Physical Therapy and Rehabilitation, University of Health Sciences, Umraniye Training and Research Hospital, Istanbul, Turkey

Keywords

costochondritis, extracorporeal shock-wave therapy, quality of life, pressure pain threshold, intra-articular steroid injection

Schlüsselwörter

Costochondritis, Extrakorporale Stoßwellentherapie, Intraartikuläre Steroid injection, Lebensqualität, Druckschmerzschwelle

online publiziert $\quad 09.09 .2020$

Bibliography

Akt Rheumatol 2021; 46: 80-87

DOI 10.1055/a-1180-8053

ISSN 0341-051X

(C) 2020. Thieme. All rights reserved.

Georg Thieme Verlag KG, Rüdigerstraße 14,

70469 Stuttgart, Germany

Correspondence

Dr. Halil Çiftçi

Thoracic Surgery

University of Health Sciences

Umraniye Training and Research Hospital

34760 Istanbul

Turkey

Tel.: + 905055023999, Fax: + 902166327124

halilciftci@gmail.com

ABSTRACT

Background This study aims to investigate the effects of extracorporeal shock-wave therapy (ESWT) and intra-articular steroid injection (IASI) on pain, depression, quality of life and pressure pain threshold (PPT) in patients with costochondritis. Methods A total of 67 patients diagnosed with costochondritis were included. Patients were divided into 2 groups. Group $1(n=34)$ received high-energy flux density (H-ESWT) $\left(>0.28 \mathrm{~mJ} / \mathrm{mm}^{2}\right)$ for a total of 7 sessions at 3-day intervals. Group $2(n=33)$ received IASI twice at 2-week intervals. At baseline and one month after treatment, Visual Analog Scale (VAS), Short Form-36(SF-36), Pittsburgh Sleep Quality Index (PSQI), Beck Depression Inventory (BDI) scores and PPT values were compared.

Results There was a statistically significant decrease in VAS scores after treatment compared with baseline scores in both groups. The PPT and SF-36 subscale scores were also statistically significantly higher $(\mathrm{p}<0.05)$. After treatment, VAS and PPT showed a significantly better improvement in Group 1 compared to Group 2. There was a significant correlation between VAS and SF-36 physical functioning as well as pain subscales in Group 1 and a significant correlation between VAS and SF-36 physical functioning in Group 2.

Conclusions Our data suggest that both treatments H-ESWT and IASI are effective in costochondritis patients. Of note, $\mathrm{H}$ ESWT has a stronger effect on pain and PPT scores.

\section{ZUSAMMENFASSUNG}

Hintergrund Ziel dieser Studie ist es, die Auswirkungen der extrakorporalen Stoßwellentherapie (ESWT) und der intraartikulären Steroidinjektion (IASI) auf Schmerzen, Depressionen, Lebensqualität und Druckschmerzschwelle (PPT) bei Patienten mit Costochondritis zu untersuchen.

Methoden Insgesamt wurden 67 Patienten mit der Diagnose einer Costochondritis eingeschlossen. Die Patienten wurden in 2 Gruppen eingeteilt. Gruppe $1(n=34)$ erhielt für insgesamt 7 Sitzungen in 3-tägigen Intervallen eine hochenergetische Flussdichte (H-ESWT) $\left(>0,28 \mathrm{~mJ} / \mathrm{mm}^{2}\right)$. Gruppe $2(\mathrm{n}=33)$ erhielt 2-mal im Abstand von 2 Wochen IASI. Zu Studienbeginn und einen Monat nach der Behandlung wurden die Werte für Visual Analog Scale (VAS), Short Form-36 (SF-36), Pittsburgh Sleep Quality Index (PSQI), Beck Depression Inventory (BDI) und PPT-Werte verglichen. 
Ergebnisse Es gab eine statistisch signifikante Abnahme der VAS-Werte nach der Behandlung im Vergleich zu den Ausgangswerten in beiden Gruppen. Die Subskalenwerte für PPT und SF-36 waren ebenfalls statistisch signifikant höher $(p<0,05)$. Nach der Behandlung zeigten VAS und PPT eine signifikant größere Verbesserung in Gruppe 1 im Vergleich zu Gruppe 2. Es bestand ein signifikanter Zusammenhang zwischen der VAS und der körperlichen Funktionsfähigkeit nach SF-36, sowie
Schmerz-Subskalen in Gruppe 1 und eine signifikante Korrelation zwischen der VAS und der körperlichen Funktionsfähigkeit nach SF-36 in Gruppe 2.

Schlussfolgerungen Unsere Daten deuten darauf hin, dass sowohl die H-ESWT als auch die IASI-Behandlung bei Patienten mit Costochondritis wirksam sind. Die H-ESWT hat dabei eine stärkere Wirkung auf Schmerzen und PPT-Scores.

\section{Introduction}

Costochondritis is a painful condition caused by inflammation of sternocostal joints without swelling. The causes of costochondritis are unknown, but genetic, viruses, and injury are possible causes. Inflammation can occur in bilateral sternocostal junction, but is usually only on one side. There is no specific diagnostic test for costocontritis. The diagnosis of costochondritis is made on the physical examination with tenderness and pain. Pain is typically reproducible by palpation and radiates to chest [1]. It affects as many as $30 \%$ of patients presenting to emergency departments with chest pain [2]. The pain may occur during physical activity or inspiration [3].

Although no consensus has been established upon the treatment of costochondritis, treatment usually focuses on pain relief with acetaminophen, non-steroidal anti-inflammatory drugs, physical therapy modalities, and intra-articular steroid injections (IASI) $[4,5]$.

Extracorporeal shock wave therapy (ESWT) is a non-invasive procedure which has been proven to be effective in treating musculoskeletal system diseases including PF, calcific tendinopathies, lateral and medial epicondylitis, and myofascial pain syndrome (MPS) [6-8]. Although the mechanism of action of ESWT in costochondritis is still unclear, the energy crisis hypothesis may explain how ESWT affects other conditions [9, 10]. The mechanisms through which ESWT exerts its therapeutic effects are thought to be increased tissue perfusion, increased vascularization, and altered pain stimuli in ischemic tissues by an increased intake of calcium.

In the literature, there are some reports investigating the efficacy of ESWT in costochondritis; however, there is a very limited number of studies comparing ESWT and IASI in this patient population. In the present study, we, therefore, aimed to compare the effects of ESWT vs. IASI on pain, depression, quality of life, and pressure pain threshold (PPT) in patients with costochondritis.

\section{Methods}

\section{Study population}

This single-blind, prospective, randomized-controlled clinical study was conducted at the University of Health Sciences, Umraniye Training and Research Hospital, Musculoskeletal Outpatient Clinic between September 2019 and February 2020. A total of 67 patients (10 males, 57 females; mean age: $43.4 \pm 13$.2 years; range, 19-67 years) with the diagnosis of costochondritis were included in the study. Inclusion criteria were as follows: having a clinical diagnosis of costochondritis; reproducible pain by palpation of costal cartilages and sternocostal ribs radiating to the chest wall; and having persistent pain at least for six months as assessed by a Visual Analog Scale (VAS) [11]. Exclusion criteria were as follows: no prior treatment including ESWT and steroid injection within the past 6 months; having a diagnosis of other cardiovascular and lung diseases; having a malignancy, vitamin D deficiency, other inflammatory disease, pregnancy, cardiac pacemaker, local infections, or severe cardiac and renal diseases. To rule out other cardiovascular and lung diseases, all patients underwent a detailed physical examination and laboratory testing. In addition, posterioanterior (PA) and lateral plain chest radiographs, electrocardiography and thoracic computed tomography $(\mathrm{CT})$ scans were obtained. A written informed consent was obtained from each patient. The study protocol was approved by the University of Health Sciences, Umraniye Training and Research Hospital Ethics Committee (06/09/2019 54132726-000-18027). The study was conducted in accordance with the principles of the Declaration of Helsinki.

\section{Randomization}

Randomization was performed using sequentially numbered, opaque, sealed envelopes. The investigators who assessed pre- and post-treatment measurements were not allowed to attend to the intervention period and were blinded to group allocation. The patients were divided into two groups. Group $1(n=34)$ received high-energy flux density (H-ESWT) $\left(0.26 \mathrm{~mJ} / \mathrm{mm}^{2}\right)$ for a total of seven sessions at 3 -day intervals. Group $2(n=33)$ received IASI for 2 times at 2 -week intervals. Data including baseline demographic characteristics of all patients were recorded. The study flow chart is shown in $>$ Fig. 1.

\section{Interventions}

The ESWT group received ESWT using Modus Inceler Medikal, Ankara, Turkey. A total of 7 sessions of focused ESWT was performed at 3-day intervals. The ESWT was applied at costal cartilages and sternocostal joints at 500 pulses/point, a total of 1,500 to 3,000 pulses/session 1.5 to 3 bars with H-ESWT $\left(>0.28 \mathrm{~mJ} / \mathrm{mm}^{2}\right)$ in each session.

The IASI group received IASI for 2 times at 2-week intervals. $2 \mathrm{~mL}$ of betamethasone was injected to each painful point by a specialist. After the patient was given the appropriate position, the costosternal joints to be injected were determined and marked with a ballpoint pen. The area to be injected was cleaned without touching it. After wearing a sterile glove, corticosteroid was injected into the joints at a 90 degree angle after negative aspiration before injection. After the injection, pneumothorax was excluded with chest radiograph. 


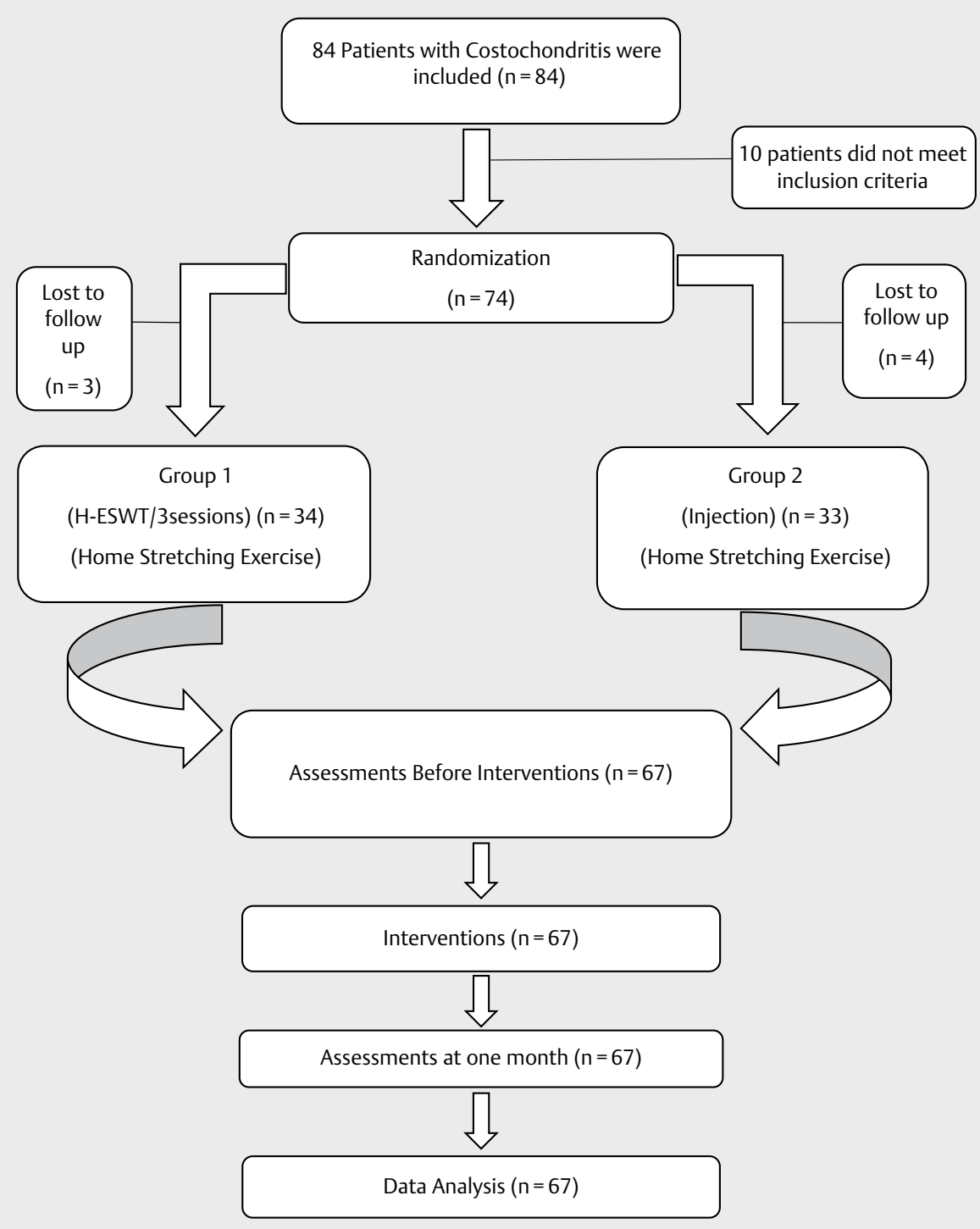

- Fig. 1 Study flow chart.

Chest stretching exercises were given to all patients in both groups. All patients were instructed about the exercises by physiotherapists and the first set of exercises were performed under the supervision of clinical physiotherapists. All patients were instructed to do 10 repetitions of each exercise set 3 times a day for 2 weeks.

\section{Primary outcome measures}

The PPT was defined as the point at which a sensation of pressure changed into a sensation of pain. The PPT was evaluated using the Baseline ${ }^{\circledR}$ Dolorimeter-22 lb Capacity (Fabrication Enterprises, NY, USA). Pressure pain in the upper trapezius was measured using a baseline dolorimeter (Pain Diagnosis and Treatment Inc., CA, USA). The instrument consists of a gauge attached to a hard rubber tip $1 \mathrm{~cm}$ in diameter. The dial gauge can be calibrated in $\mathrm{kg}$ or pounds (lb), ranging from 1 to $30 \mathrm{~kg}$ or from 1 to $60 \mathrm{lb}$ at an interval of $0.25 \mathrm{~kg}$ or $0.5 \mathrm{lb}$. The force recorded is the amount of pressure which causes pain. Inter-individual reliability is good to excellent (interclass correlation coefficient $=0.75-0.89$ ) [12].

\section{Secondary outcome measures}

All pre- (at baseline) and post-treatment (at one month) measurements were evaluated by a single investigator. The VAS was used to evaluate pain severity. The score ranges from 0 to 10 , and 0 indicates no pain, while 10 indicates unbearable pain.

The Short Form-36 (SF-36), which consists of 8 subscales and 36 items, was used to evaluate physical and mental health of the patients. It is a valid survey for the evaluation of quality of life and consists of the following subscales: physical functioning (PF), limitations of daily activities by difficulty in physical role (DPR), pain severity by bodily pain (BP), rating of health by general health $(\mathrm{GH})$, energy and fatigue by vitality (VT), limitations of daily activities by 
social functioning (SF), and limitation of regular daily activities by difficulty in emotional role (DER) and mental health (MH) [13].

The Beck Depression Inventory (BDI) was used to evaluate depressive symptomatology. It is a 21 -item, self-reporting questionnaire which measures characteristic attitudes and symptoms of depression. The maximum total score is 63 , and higher scores indicate greater symptom severity. The validity and reliability studies of the Turkish version of the BDI have been shown [14].

\section{Statistical analysis}

A power analysis was performed using the $G$ * Power version 3.1.0 software (Heinrich Heine University, Düsseldorf, Germany) and the sample size was calculated. Based on an alpha value of 0.05 for statistical significance, 33 patients in each group could achieve $80 \%$ statistical power. Finally, a total of 66 patients were planned to be recruited in both groups. Assuming a dropout of $15 \%, 75$ patients were expected to be included.

Statistical analysis was performed using the Statistical Package for the Social Sciences (SPSS) version 25.0 software (IBM Corp., Armonk, NY, USA). Descriptive data were expressed in mean \pm standard deviation (SD), or number and frequency. The KolmogorovSmirnov test was used for normality test of data. The Mann-Whitney $U$ test was performed to analyze non-parametric data. The Wilcoxon signed-rank test was used to compare non-normally distributed data. The Pearson correlation analysis was done to analyze possible correlations between the variables. A $p$ value of $<0.05$ was considered statistically significant.

\section{Results}

Of a total of 67 patients, 57 were females and 10 were males with a mean age of $43.4 \pm 13.2$ (range, 19-67) years. Totally, there were 34 (50.74\%) patients in Group 1 and 33 patients (49.26\%) in Group 2. There were no statistically significant differences in the baseline demographic characteristics between the groups ( $p>0.05)$. Demographic characteristics of the patients are shown in > Table 1.

No ESWT-related side effects or tissue damage were seen in any of the patients in the ESWT group. Also, there was no statistically significant difference in the baseline VAS, BDI, PPT, SF-36 subscale scores between the groups ( $p>0.05)$. However, there was a statistically significant decrease in the VAS scores at month after the treatment in both groups, compared to baseline scores $(p<0.05)$, although the decrease was statistically significantly higher in the ESWT group $(p<0.05)$. In addition, there was a statistically significant increase in the SF-36 subscale and PPT scores at one month after the treatment in both groups $(p<0.05)$ with a statistically significantly higher increase in the ESWT group $(p<0.05)$. Although there was a statistically significant decrease in the BDI scores at one month after the treatment in both groups, compared to baseline scores ( $p=0.854)$, there was no statically significant difference between the groups. Pre- and post-treatment VAS, BDI, SF-36, and PPT scores in Group 1 and Group 2 are presented in > Table 2.

The correlation analysis revealed a moderate, negative, and statistically significant relationship between the changes in the VAS scores and changes in the SF-36 PF scores $(r=-0.541)$ after the treatment in the ESWT group. In addition, there was a weak, negative, and statistically significant relationship between the changes in the VAS and the changes in the SF-36 BP subscale scores $(r=$ - 0.472) after the treatment in the ESWT group. In the IASI group,

- Table 1 Baseline demographic characteristics of the patients.

\begin{tabular}{|c|c|c|c|c|}
\hline & & $\begin{array}{l}\text { Group } 1 \\
\text { (H-ESWT) }\end{array}$ & $\begin{array}{l}\text { Group } 2 \\
\text { (IASI) }\end{array}$ & Total \\
\hline & & n (\%) & n (\%) & n (\%) \\
\hline Age, years, mean \pm SD (range) & & $19-44(33.6 \pm 13.4)$ & $23-47(33.8 \pm 13.2)$ & $19-47(33.4 \pm 13.2)$ \\
\hline \multirow[t]{2}{*}{ Sex, n (\%) } & Male & $5(14.7)$ & $5(14.2)$ & $10(14.9)$ \\
\hline & Female & $29(85.3)$ & $28(84.8)$ & $57(85.1)$ \\
\hline \multirow[t]{2}{*}{ Marital status, n (\%) } & Married & $29(85.3)$ & $25(75.8)$ & $54(80.6)$ \\
\hline & Single & $5(14.7)$ & $8(24.2)$ & $13(19.4)$ \\
\hline \multirow[t]{5}{*}{ Educational status, n (\%) } & None & $2(5.9)$ & $1(3.0)$ & $3(4.5)$ \\
\hline & Primary & $17(50.0)$ & $15(45.5)$ & $32(47.8)$ \\
\hline & Secondary & $6(17.6)$ & $7(21.2)$ & $13(19.4)$ \\
\hline & High & $2(5.9)$ & $3(9.1)$ & $5(7.5)$ \\
\hline & Graduate/Post graduate & $7(20.6)$ & $7(21.2)$ & $14(20.9)$ \\
\hline \multirow[t]{3}{*}{ Income level, n (\%) } & Low & $23(67.6)$ & $17(51.5)$ & 40 (59.7) \\
\hline & Middle & $5(14.7)$ & $10(30.3)$ & $15(22.4)$ \\
\hline & High & $6(17.6)$ & $6(18.2)$ & 12 (17.9) \\
\hline
\end{tabular}

ESWT, extracorporeal shock wave therapy; IASI, intra-articular steroid injection; SD, standard deviation. 
- Table 2 Comparison of VAS, BDI, SF-36, and pain threshold scores before and after treatment in ESWT and IASI groups.

\begin{tabular}{|c|c|c|c|c|}
\hline & & $\begin{array}{l}\text { Group } 1 \\
\text { (H-ESWT) }\end{array}$ & $\begin{array}{l}\text { Group } 2 \\
\text { (IASI) }\end{array}$ & (inter-group) $p^{1}$ \\
\hline & & Mean \pm SD (range) & Mean \pm SD (range) & \\
\hline \multirow[t]{3}{*}{ VAS } & Pre-treatment & $6.35 \pm 1.04$ & $6.33 \pm 0.98$ & 0.984 \\
\hline & Post-treatment & $2.73 \pm 0.93$ & $3.66 \pm 0.98$ & $<0.05^{*}$ \\
\hline & Pre-post-treatment $p^{2}$ & $<0.05^{*}$ & $<0.05^{*}$ & \\
\hline \multirow[t]{3}{*}{ BDI } & Pre-treatment & $14.29 \pm 8.58$ & $14.45 \pm 8.09$ & 0.905 \\
\hline & Post-treatment & $9.82 \pm 6.14$ & $10.12 \pm 6.30$ & 0.845 \\
\hline & Pre-post-treatment $p^{2}$ & $<0.05^{*}$ & $<0.05^{*}$ & \\
\hline \multirow[t]{3}{*}{ SF-36 PF } & Pre-treatment & $79.8 \pm 13.9$ & $81.6 \pm 15.0$ & 0.478 \\
\hline & Post-treatment & $92.7 \pm 9.14$ & $90.1 \pm 11.4$ & 0.301 \\
\hline & Pre-post-treatment $p^{2}$ & $<0.05^{*}$ & $<0.05^{*}$ & \\
\hline \multirow[t]{3}{*}{ SF-36 DPR } & Pre-treatment & $44.1 \pm 28.9$ & $59.0 \pm 32.3$ & 0.049 \\
\hline & Post-treatment & $89.7 \pm 19.5$ & $81.0 \pm 25.0$ & 0.119 \\
\hline & Pre-post-treatment $p^{2}$ & $<0.05^{*}$ & $<0.05^{*}$ & \\
\hline \multirow[t]{3}{*}{ SF-36 DER } & Pre-treatment & $41.1 \pm 27.2$ & $61.6 \pm 29.0(35)$ & $0.008^{*}$ \\
\hline & Post-treatment & $87.2 \pm 18.3(65)$ & $86.8 \pm 20.3(45)$ & 0.935 \\
\hline & Pre-post-treatment $p^{2}$ & $<0.05^{*}$ & $<0.05^{*}$ & \\
\hline \multirow[t]{3}{*}{ SF-36 VT } & Pre-treatment & $40.1 \pm 24.2(32)$ & $39.5 \pm 24.0(32)$ & 0.920 \\
\hline & Post-treatment & $56.4 \pm 21.6(60)$ & $48.6 \pm 23.5(40)$ & 0.101 \\
\hline & Pre-post-treatment $p^{2}$ & $<0.05^{*}$ & $<0.05^{*}$ & \\
\hline \multirow[t]{3}{*}{ SF-36 MH } & Pre-treatment & $52.4 \pm 21.6(25)$ & $53.2 \pm 21.3(32.5)$ & 0.860 \\
\hline & Post-treatment & $65.0 \pm 18.6(62.5)$ & $61.2 \pm 20.8(37.5)$ & 0.428 \\
\hline & Pre-post-treatment $p^{2}$ & $<0.05^{*}$ & $<0.05^{*}$ & \\
\hline \multirow[t]{3}{*}{ SF-36 SF } & Pre-treatment & $66.7 \pm 23.9(32.5)$ & $67.6 \pm 25.1(32.5)$ & 0.888 \\
\hline & Post-treatment & $84.2 \pm 13.0(62.5)$ & $79.3 \pm 17.5(45)$ & 0.194 \\
\hline & Pre-post-treatment $p^{2}$ & $<0.05^{*}$ & $<0.05^{*}$ & \\
\hline \multirow[t]{3}{*}{ SF-36 BP } & Pre-treatment & $53.7 \pm 25.0(30)$ & $54.2 \pm 25.8(30)$ & 0.929 \\
\hline & Post-treatment & $80.5 \pm 14.2(60)$ & $74.0 \pm 20.4(40)$ & 0.135 \\
\hline & Pre-post-treatment $p^{2}$ & $<0.05^{*}$ & $<0.05^{*}$ & \\
\hline \multirow[t]{3}{*}{ SF-36 GH } & Pre-treatment & $55.1 \pm 22.2$ & $54.3 \pm 22.1$ & 0.885 \\
\hline & Post-treatment & $65.4 \pm 20.8$ & $61.2 \pm 20.8$ & 0.410 \\
\hline & Pre-post-treatment $p^{2}$ & $<0.05^{*}$ & $<0.05^{*}$ & \\
\hline \multirow[t]{3}{*}{ PPT } & Pre-treatment & $3.93 \pm 1.04$ & $3.98 \pm 1.09$ & 0.793 \\
\hline & Post-treatment & $11.7 \pm 1.28$ & $10.8 \pm 1.66$ & $<0.05^{*}$ \\
\hline & Pre-post-treatment $p^{2}$ & $<0.05^{*}$ & $<0.05^{*}$ & \\
\hline
\end{tabular}

ESWT, extracorporeal shock wave therapy; IASI, intra-articular steroid injection; SD, standard deviation; VAS, Visual Analog Scale; SF-36 PF, Short Form-36 physical functioning; SF-36 DPR, Short Form-36 difficulty in physical role; SF-36 DER, Short Form-36 difficulty in emotional role; SF-36 VT, Short Form-36 vitality; SF-36 MH, Short Form-36 mental health; SF-36 SF, Short Form-36 social functioning; SF-36 BP, Short Form-36 bodily pain; SF-36 GH, Short Form-36 general health; BDI, Beck Depression Inventory; PPT, pressure pain threshold; 1Mann-Whitney U test; 2Wilcoxon signedrank test ${ }^{*} p<0.05$.

there was also a weak, negative, and statistically significant relationship between the changes in the SF-36 PF and the changes in the VAS scores $(r=-0.419)$ after the treatment. The results of the correlation analysis of all scales in the ESWT and control groups are summarized in > Table 3.

\section{Discussion}

In the present study, we investigated the effects of ESWT and IASI on quality of life, mental health, and PPT in patients with costochondritis. Our study results showed that that $\mathrm{H}$-ESWT was more effective than IASI on pain, quality of life, and PPT scores in this patient population. 
- Table 3 Correlation analysis results.

\begin{tabular}{|c|c|c|c|}
\hline Group & & & VAS \\
\hline \multirow{20}{*}{$\begin{array}{l}\text { Group } 1 \\
\text { (H-ESWT) }\end{array}$} & \multirow[t]{2}{*}{ BDI } & $r$ & 0.176 \\
\hline & & $\mathrm{p}$ & 0.319 \\
\hline & \multirow[t]{2}{*}{ SF-36 PF } & $r$ & $-0.541^{* *}$ \\
\hline & & $\mathrm{p}$ & 0.001 \\
\hline & \multirow[t]{2}{*}{ SF-36 DPR } & $r$ & -0.278 \\
\hline & & $p$ & 0.111 \\
\hline & \multirow[t]{2}{*}{ SF-36 DER } & $r$ & -0.064 \\
\hline & & $\mathrm{p}$ & 0.721 \\
\hline & \multirow[t]{2}{*}{ SF-36 VT } & $r$ & -0.119 \\
\hline & & $\mathrm{p}$ & 0.501 \\
\hline & \multirow[t]{2}{*}{ SF-36 MH } & $r$ & -0.119 \\
\hline & & $\mathrm{p}$ & 0.501 \\
\hline & \multirow[t]{2}{*}{ SF-36 SF } & $r$ & -0.267 \\
\hline & & $\mathrm{p}$ & 0.126 \\
\hline & \multirow[t]{2}{*}{ BP } & $r$ & $-0.472 * *$ \\
\hline & & $\mathrm{p}$ & 0.005 \\
\hline & \multirow[t]{2}{*}{$\mathrm{GH}$} & $r$ & -0.158 \\
\hline & & $\mathrm{p}$ & 0.372 \\
\hline & \multirow[t]{2}{*}{ PPT } & $r$ & -0.161 \\
\hline & & $\mathrm{p}$ & 0.362 \\
\hline \multirow[t]{20}{*}{ Group 2 (ISAI) } & \multirow[t]{2}{*}{ BDI } & $r$ & 0.192 \\
\hline & & $\mathrm{p}$ & 0.286 \\
\hline & \multirow[t]{2}{*}{ SF-36 PF } & $r$ & $-0.419^{* *}$ \\
\hline & & $\mathrm{p}$ & 0.015 \\
\hline & \multirow[t]{2}{*}{ SF-36 DPR } & $r$ & -0.271 \\
\hline & & $\mathrm{p}$ & 0.127 \\
\hline & \multirow[t]{2}{*}{ SF-36 DER } & $r$ & 0.237 \\
\hline & & $\mathrm{p}$ & 0.184 \\
\hline & \multirow[t]{2}{*}{ SF-36 VT } & $r$ & 0.121 \\
\hline & & $\mathrm{p}$ & 0.502 \\
\hline & \multirow[t]{2}{*}{ SF-36 MH } & $r$ & 0.162 \\
\hline & & $p$ & 0.369 \\
\hline & \multirow[t]{2}{*}{ SF-36 SF } & $r$ & -0.171 \\
\hline & & $\mathrm{p}$ & 0.342 \\
\hline & \multirow[t]{2}{*}{$\mathrm{BP}$} & $r$ & -0.095 \\
\hline & & $\mathrm{p}$ & 0.600 \\
\hline & \multirow[t]{2}{*}{$\mathrm{GH}$} & $r$ & 0.129 \\
\hline & & $\mathrm{p}$ & 0.474 \\
\hline & \multirow[t]{2}{*}{ PPT } & $r$ & -0.137 \\
\hline & & $\mathrm{p}$ & 0.448 \\
\hline
\end{tabular}

ESWT, extracorporeal shock wave therapy; IASI, intra-articular steroid injection; SD, standard deviation; VAS, Visual Analog Scale; SF-36 PF, Short Form-36 physical functioning; SF-36 DPR, Short Form-36 difficulty in physical role; SF-36 DER, Short Form-36 difficulty in emotional role; SF-36 VT, Short Form-36 vitality; SF-36 $\mathrm{MH}$, Short Form-36 mental health; SF-36 SF, Short Form-36 social functioning; SF-36 BP, Short Form-36 bodily pain; SF-36 GH, Short Form-36 general health; BDI, Beck Depression Inventory; PPT, pressure pain threshold; Pearson correlation analysis ${ }^{*} \mathrm{p}<0.05$.
Steroids have a broad set of physiological effects in the treatment and prognosis of inflammatory diseases [15]. Ostergaard et al. [16] showed that one or more injections into a joint with aseptic arthritis could significantly alter the joint status as pain decreased and joint mobility increased.

Extracorporeal shock wave therapy is a proven treatment modality in several conditions such as calcific tendinopathies, lateral and medial epicondylitis, and MPS [6-8]. Based on the literature data, in the present study, we used this method vs. IASI in patients with costochondritis which is an inflammatory condition and responds well to anti-inflammatory drugs. In general, ESWT exerts its effects through mechanotransduction which produces pressure and delivers tensile and shearing forces by shock waves to the cells and, therefore, the extracellular matrix messengers are liberated and a varying number and groups of genes in the cell nucleus are activated [17]. Although the working mechanism of ESWT has not been fully demonstrated, several possible mechanisms have been proposed. In a study, ESWT was shown to inhibit overstimulation of the nerves and nociceptors and increased the blood flow, resulting in to pain relief through reduced muscle stiffness and contractions [17] Similarly, ESWT disrupted non-myelinated fibers, decreased the production of substance $P$ level at the dorsal root ganglia, and relieved musculoskeletal pain $[18,19]$.

In general, ESWT can be classified into 3 categories based on its energy levels: low-energy $\left(<0.08 \mathrm{~mJ} / \mathrm{mm}^{2}\right)$, medium-energy $(0.08$ $\left.0.28 \mathrm{~mJ} / \mathrm{mm}^{2}\right)$, and high-energy $\left(0.28 \mathrm{~mJ} / \mathrm{mm}^{2}\right)$ [20-22]. High-energy ESWT can induce fragmentation and destruction of solid bodies such as kidney stones, gallstones, and body tissues and is often requires sedation or anesthesia, while low-energy ESWT (L-ESWT) exerts its therapeutic effect through neurophysiological mechanisms and does not require the use of sedation or anesthesia and can be applied in the outpatient setting [23]. However, there is no consensus on the optimal therapeutic intensity and dose-response relation [24].

In a study conducted by Müller et al., [25] focused H-ESWT was used in MPS patients and decreased VAS scores at 3 months. Gur et al. [26] used focused $\mathrm{H}$-ESWT and compared 3 sessions vs. a single session of treatment in MPS patients and reported that 3-session treatment improved pain more effectively. In another study, Park et al. [27] examined the efficacy of H-ESWT vs. L-ESWT in MPS patients of the upper trapezius and found improvements in the Verbal Numeric Pain Scale and pressure threshold in both groups, although it was statistically significant in the H-ESWT group. Similarly, Chow et al. [28] divided 57 patients with chronic heel pain into 3 groups to receive either fixed energy density or maximum tolerable energy density or control treatment ( 30 impulses at a frequency of $3 \mathrm{~Hz}$ at the lowest level $\left[0.03 \mathrm{~m} / / \mathrm{mm}^{2}\right]$ ) once a week for 3 weeks. The maximum tolerable energy density group showed a significant improvement in the $\mathrm{FFI}$ and pain scores, while the control group had no improvement after treatment. This finding indicates that the delivery of ESWT with a maximum tolerable energy density is more effective than a fixed energy density. In a meta-analysis of randomized, placebo-controlled trials, the efficacy of different energy levels of ESWT was examined in patients with plantar fasciitis and focused ESWT was found to be more effective than radial ESWT and $\mathrm{H}$-ESWT/medium energy-ESWT were more effective than L-ESWT in the long-term follow-up [29]. In addition, anesthetic premedi- 
cation was shown to reduce the effectiveness of treatment. Altogether, these findings suggest that an increased number of sessions of ESWT and its use in high-energy density may promote its effectiveness on pain, depression, quality of life, and PPT. Consistent with the previous studies, we used H-ESWT for 7 sessions in our study group. In the current study, we found statistically significant improvements in the SF-36 and BDI scores and pain relief in our patients with costochondritis after the treatment. These findings indicate the importance of $\mathrm{H}$-ESWT for a high number of sessions in pain management in patients with costochondritis. In addition, we found a significant correlation between the VAS and SF-36 PF and BP subscale scores in the ESWT group.

Weak correlation between SF-36 BP and VAS after treatment in the H-ESWT group indicates a faster improvement in ESWT group in patients' pain. However, there was a weak, negative, and statistically significant relationship between the changes in the SF-36 PF and the changes in the VAS scores in the IASI group, suggesting that H-ESWT for a higher number of sessions than a lower number of sessions may be a more effective treatment than IASI.

Nonetheless, there are some limitations to this study. First, relatively small sample size and the presence of a non-treatment group might have affected the results. Second, as the present study included only costochondritis patients, the results cannot be generalized to the general population. Third, the treatment results were only able to be evaluated at one month and, thus, its long-term outcomes are unclear. Further large-scale, long-term studies are needed to confirm these findings.

\section{Conclusions}

In conclusion, pain management is of utmost importance in the treatment of costochondritis with reduced pain and improved quality of life, depression, and PPT scores. As data regarding the efficacy of ESWT vs. IASI are scarce, the present study provides valuable implications to guide physicians in the treatment of costochondritis. Based on our study results, we suggest that H-ESWT for a high number of sessions is more effective than IASI in patients with costochondritis.

\section{Competing interest}

The authors declare that they have no conflict of interest.

\section{References}

[1] Schumann JA, Parente JJ. Costochondritis. StatPearls [Internet].Treasure Island (FL): StatPearls Publishing; 2019 Jan-2019 Dec 11

[2] Disla E, Rhim HR, Reddy A et al. Costochondritis. A prospective analysis in an emergency department setting. Arch Intern Med 1994; 154: 2466-2469

[3] Semble EL, Wise CM. Chest pain: a rheumatologist's perspective. South Med J 1988; 81: 64-68

[4] How J, Volz G, Doe S et al. The causes of musculoskeletal chest pain in patients admitted to hospital with suspected myocardial infarction. Eur J Intern Med 2005; 16: 432-436
[5] Spalding L, Reay E, Kelly C. Cause and outcome of atypical chest pain in patients admitted to hospital. J R Soc Med 2003; 96: 122-125. DOI: 10.1258/jrsm.96.3.122

[6] Pan PJ, Chou CL, Chiou H] et al. Extracorporeal shock wave therapy for chronic calcific tendinitis of the shoulders: a functional and sonographic study. Arch Phys Med Rehabil 2003; 84: 988-993

[7] Perlick L, Schiffmann R, Kraft CN et al. Extracorporal shock wave treatment of the achilles tendinitis: Experimental and preliminary clinical results. Z Orthop Ihre Grenzgeb 2002; 140: 275-280

[8] Ordahan B, Türkoğlu T, Karahan AY et al. Extracorporeal shockwave therapy versus kinesiology taping in the management of plantar fascitis: a randomized clinical trial. Arch Rheumatol 2017; 32: 227-233. DOI: 10.5606/ArchRheumatol.2017.6059

[9] Ottoman C, Hartmann B, Tyler JH et al. Prospective randomized trial of accelerated re-epithelization of skin graft donor sites using extracorporeal shock wave therapy. J Am Coll Surg 2010; 211: 361-367

[10] Rompe JD, Hope C, Küllmer K et al. Analgesic effect of extracorporeal shock-wave therapy on chronic tennis elbow. J Bone Joint Surg Br 1996; 78: 233-237

[11] Gallagher EJ, Liebman M, Bijur PE. Prospective validity of clinically important changes in pain severity measured on visual analog scale. Ann Emerg Med 2001; 38: 633-638

[12] Collins SL, Moore RA, McQuay H]. The visual analogue pain intensity scale: what is moderate pain in millimetres? Pain 1997; 72: 95-97

[13] Koçyiğit H, Aydemir Ö, Fişek $G$ et al. Reliability and validity of the Turkish version of short form-36. Ilaç ve Tedavisi Dergisi 1999; 2: 12

[14] Sahin NH. Use of the beck depression inventory with Turkish university students: reliability, validity and factor analysis. Turkish. Journal of Psychology 1989; 7: 3-1322

[15] Oxlund $\mathrm{H}$. The Influence of a local injection of cortisol on the mechanical properties of tendons and ligaments and the indirect effect on skin. Acta Orthopaedica Scandinavica 1980; 51: 1-6, 231-238

[16] Ostergaard M, Halberg P. Intra-articular corticosteroids in arthritic disease: a guide to treatment. BioDrugs 1998; 9: 95-103

[17] Zimmermann R, Cumpanas A, Miclea F et al. Extracorporeal shock wave therapy for the treatment of chronic pelvic pain syndrome in males: a randomised, double-blind, placebo-controlled study. Eur Urol 2009; 56: 418-424

[18] Hausdorf J, Lemmens MA, Heck KD et al. M. Selective loss of unmyelinated nerve fibers after extracorporeal shockwave application to the musculoskeletal system. Neuroscience 2008; 155: 138-144

[19] Hausdorf J, Lemmens MA, Kaplan S et al. Extracorporeal shock wave application to the distal femur of rabbits diminishes the number of neurons immunoreactive for substance $P$ in dorsal root ganglia $L 5$. Brain Res 2008; 1207: 96-101

[20] Rompe JD, Furia J, Weil L et al. Shock wave therapy for chronic plantar fasciopathy. Br Med Bull 2007; 81-82: 183-208. DOI: 10.1093/bmb/ Idm005

[21] Gollwitzer H, Diehl P, Von Korff A et al. Extracorporeal shock wave therapy for chronic painful heel syndrome: a prospective, double blind, randomized trial assessing the efficacy of a new electromagnetic shock wave device. J Foot Ankle Surg 2007; 46: 348-357

[22] Liang HW, Wang TG, Chen WS et al. Thinner plantar fascia predicts decreased pain after extracorporeal shock wave therapy. Clin Orthop Relat Res 2007; 460: 219-225

[23] Verstraelen FU, In den Kleef N], Jansen L et al. High-energy versus low-energy extracorporeal shock wave therapy for calcifying tendinitis of the shoulder: which is superior? A meta-analysis. Clin Orthop Relat Res 2014; 472: 2816-2825

[24] Thiel M. Application of shock waves in medicine. Clin Orthop Relat Res 2001; 387: 18-21 
[25] Müller-Ehrenberg H, Licht G. Diagnosis and therapy of myofascial pain syndrome with focused shock waves (ESWT). Med Orthop Tech 2005; 5: $1-6$

[26] Gür A, Koca I, Karagüllü $\mathrm{H}$ et al. Comparision of the effectiveness of two different extracorporeal shockwave therapy regimens in the treatment of patients with myofascial pain syndrome. Arch Rheumatol 2014; 29: 186-193

[27] Park KD, Lee WY, Park MH et al. High- versus low-energy extracorporeal shock-wave therapy for myofascial pain syndrome of upper trapezius: a prospective randomized single blinded pilot study. Medicine(Baltimore) 2018; 97: e11432
[28] Chow IH, Cheing GL. Comparison of different energy densities of extracorporeal shock wave therapy (ESWT) for the management of chronic heel pain. Clin Rehabil 2007; 21: 131-141

[29] Wang YC, Chen SJ, Huang PJ et al. Efficacy of different energy levels used in focused and radial extracorporeal shockwave therapy in the treatment of plantar fasciitis: a meta-analysis of randomized placebo-controlled trials. J Clin Med 2019; 8 pii: E1497 